NASA Technical Memorandum 107500

IECEC-97347

\title{
Design and Analysis of the Aperture Shield Assembly for a Space Solar Receiver
}

Hal J. Strumpf, Tuan Trinh, William Westelaken, Christopher Krystkowiak, and Vahe Avanessian AlliedSignal Aerospace Equipment Systems

Torrance, California

Thomas W. Kerslake

Lewis Research Center

Cleveland, Ohio

Prepared for the

32nd Intersociety Energy Conversion Engineering Conference cosponsored by AIChE, ANS, SAE, AIAA, ASME, and IEEE Honolulu, Hawaii, July 27-August 1, 1997

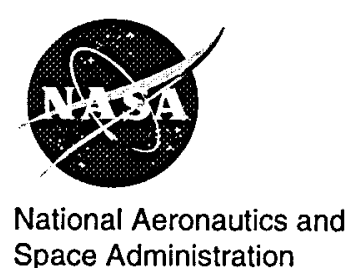

Space Administration 


$$
\cdot \quad \cdots
$$




\title{
DESIGN AND ANALYSIS OF THE APERTURE SHIELD ASSEMBLY FOR A SPACE SOLAR RECEIVER
}

\author{
Hal J. Strumpf \\ Tuan Trinh \\ William Westelaken \\ Christopher Krystkowiak \\ Vahe Avanessian \\ AlliedSignal Aerospace Equipment Systems \\ 2525 West 190 th Street \\ Torrance, California 90509 \\ Phone (310) 512-3359 - Fax (310) 512-4128 \\ and \\ Thomas W. Kerslake \\ NASA Lewis Research Center \\ Cleveland, Ohio 44135 \\ Phone (216) 433-5373 Fax (216) 433-2995
}

\section{ABSTRACT}

A joint U.S./Russia program has been conducted to design, develop, fabricate, launch, and operate the world's first space solar dynamic power system on the Russian Space Station Mir. The goal of the program was to demonstrate and confirm that solar dynamic power systems are viable for future space applications such as the International Space Station (ISS). The major components of the system include a solar receiver, a closed Brayton cycle power conversion unit, a power conditioning and control unit, a solar concentrator, a radiator, a thermal control system, and a Space Shuttle carrier. Unfortunately, the mission was demanifested from the ISS Phase 1 Space Shuttle Program in 1996. However, NASA Lewis is proposing to use the fabricated flight hardware as part of an all-American flight demonstration on the ISS in 2002.

The present paper concerns the design and analysis of the solar receiver aperture shield assembly. The aperture shield assembly comprises the front face of the cylindrical receiver and is located at the focal plane of the solar concentrator. The aperture shield assembly is a critical component that protects the solar receiver structure from highly concentrated solar fluxes during concentrator off-pointing events.
A full-size aperture shield assembly was fabricated. This unit was essentially identical to the flight configuration, with the exception of materials substitution. In addition, a thermal shock test aperture shield assembly was fabricated. This test article utilized the flight materials and was used for high-flux testing in the solar simulator test rig at NASA Lewis. This testing is described in a companion paper.

\section{NOMENCLATURE}

CBC Closed Brayton Cycle

ISS International Space Station

MLI Multilayer Insulation

PGS Power Generation System

SDFD Solar Dynamic Flight Demonstration

\section{INTRODUCTION}

AlliedSignal Aerospace Equipment Systems, under NASALewis Research Center Contract NAS3-26970, participated in a U.S./Russia program to design, fabricate, launch, and operate a joint solar dynamic flight experiment on Space Station Mir. The goal of the program was to demonstrate and confirm that solar dynamic power systems are viable for future space applications 
such as the International Space Station. AlliedSignal was responsible for the power generation system (PGS). The nominal PGS output power is $2 \mathrm{kw}(\mathrm{e})$.

The PGS comprises a heat receiver, a closed Brayton cycle (CBC) power conversion unit, and a power conditioning and control unit. The Russian firm, RSC-Energia, was responsible for the concentrator, radiator, thermal control system, and Space Shuttle carrier. System integration was performed jointly by NASA- Lewis and RSC-Energia.

The concentrator captures the solar rays and focuses the concentrated energy through the receiver aperture and onto the inner surface of the receiver. This concentrated energy heats the $\mathrm{CBC}$ working fluid, an inert gas mixture of xenon and helium with a molecular weight of 83.8. The heated working fluid is expanded in a turbine, driving an electrical generator and a compressor that circulates the working fluid. Cycle waste heat is rejected to the radiator and ultimately to space. A recuperator increases thermal efficiency by recirculating thermal energy in the cycle.

The present paper concerns the design and analysis of the solar receiver aperture shield assembly. The aperture shield comprises the front face of the cylindrical receiver and is located at the focal plane of the solar concentrator. The aperture shield assembly is a critical component that protects the solar receiver structure from highly concentrated solar fluxes during concentrator off-pointing events.

The position of the aperture shield in the receiver is shown in Figure 1 (Strumpf, et al, 1996). The 9.45-in.-dia aperture of the receiver accepts the solar flux from the concentrator. In addition to defining the aperture position, the aperture shield assembly must accept the steady-state spillage from the concentrator, as well as any fluxes encountered during sun acquisition or emergency off-pointing events. The program requirement was to accommodate direct impingement of the full solar image for a one-hour period.

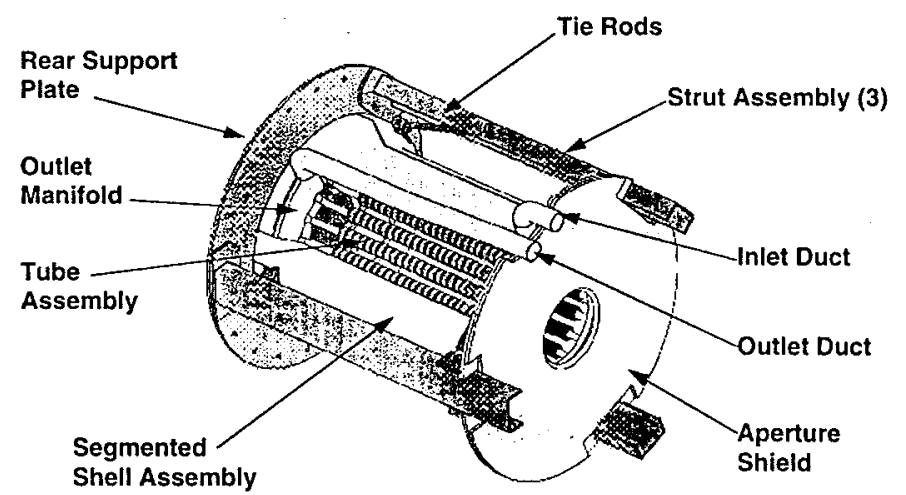

FIGURE 1. SOLAR RECEIVER ASSEMBLY
The solar dynamic flight demonstration (SDFD) program was to operate a system on Mir for a period of up to one year starting in late 1997 (Wanhainen and Tyburski, 1995). Unfortunately, the mission was demanifested from the ISS Phase I Space Shuttle program in 1996. However, substantial flight hardware, including the solar receiver, was fabricated. NASA Lewis is proposing to use the fabricated flight hardware as part of an all-American flight demonstration on the ISS in 2002.

\section{APERTURE SHIELD DESIGN HISTORY AND CURRENT APPROACH}

Previous designs for receiver aperture shield assemblies, such as for the solar dynamic ground test demonstration program, utilized a circumferentially segmented graphite aperture shield (Strumpf, et al, 1993). With the segmentation, low coefficient of thermal expansion, and high-temperature capability, the shield could accommodate the required thermal loads. However, the relatively low strength of the brittle graphite would result in significant problems during launch, requiring extremely complex design solutions.

For the SDFD system, a refractory metal configuration was used. A series of metallic foils, separated by spacers and tied together by refractory metal wire, provides the needed thermal and structural support. The shield resembles high-temperature multilayer insulation (MLI) and is indeed similar to the insulation system used on the receiver (Strumpf, et al, 1995). Design details are presented below.

\section{DESIGN DESCRIPTION}

The aperture shield assembly comprises a series of refractory metal foil layers separated by refractory metal screens in the hottest region (closest to the concentrator) and ceramic spaces in the cooler regions. While the ceramic material is a better insulator than the screens, the temperature in the hottest regions is too high to use the ceramic. The foil layers ( 40 total) and screens are either tungsten or molybdenum, depending on the temperature requirement. A cross-section of the aperture shield is shown in Figure 2.

The foil stackup is mounted to a stainless steel backplate that provides assembly and structural support for launch loads. The backplate is shown in Figure 3. The machined pockets are designed to save weight and provide flexibility to accommodate thermal gradients in the plate.

The layers are stitched together and mounted to the support plate using tungsten attachment wire. A center refractory metal support ring adds structure to the foil stackup and defines the aperture opening for the receiver. The ring material is tungsten $/ 25$ percent rhenium. For thermal growth and fabrication ease, the ring is segmented into eight circumferential sections.

The top of the stackup is enclosed by a tungsten screen, which provides support for the attachment wires. This top screen is also segmented. The top foil layer, as well as the center support ring, is grit blasted to reduce reflectivity, especially specular reflectivity. Reflected concentrated sunlight could cause significant hot zones in the concentrator, and is undesirable. At the outer circumference, a stainless steel skirt encloses the outer edges of the foil layers. 


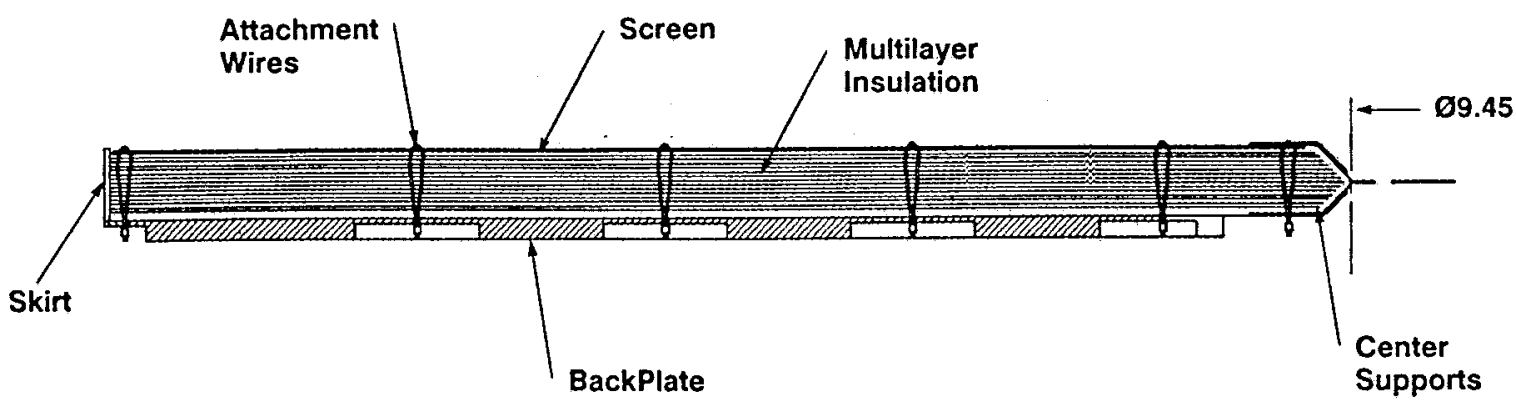

FIGURE 2. APERTURE SHIELD CROSS SECTION

$1 G-26774$

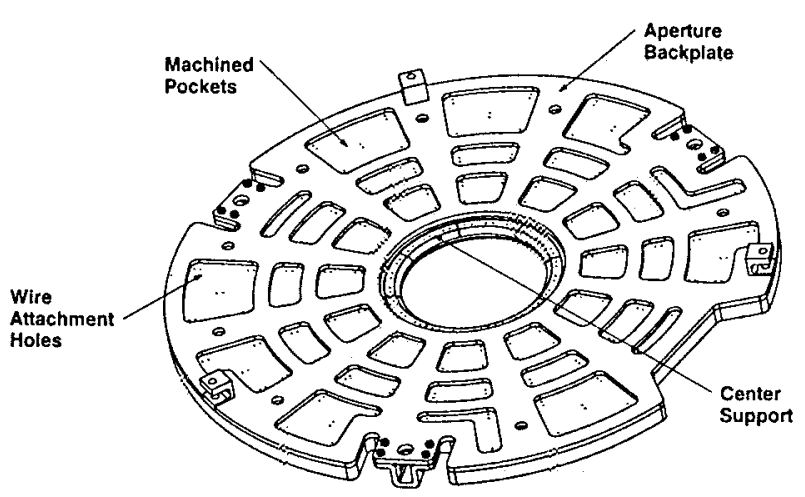

$16-20 \pi 5$

FIGURE 3. APERTURE SHIELD BACK VIEW

A section of the aperture assembly is shown in Figure 4 . A front view of the assembly is shown in Figure 5. The mounting links (three axial and three tangential) provide independent mounting to the PGS support structure. The shield diameter is approximately $1 \mathrm{~m}$.

\section{ON-ORBIT THERMAL ANALYSIS}

Thermal models were created to predict the aperture shield temperatures in response to various scenarios. These include normal operation, emergency off-pointing for up to $60 \mathrm{~min}$, and initial misalignment of the concentrator/receiver system after launch.

The models were run on the AlliedSignal Thermal Analyzer Program, a finite-difference in-house code similar to commercially available thermal analysis computer codes. A simplified schematic of the model is shown in Figure 6. Although there are many radial and circumferential nodes, to simplify the modeling effort, there are only two nodes in the foil stackup direction. Foil stackup conductances are derived from correlated data provided by Aerospace Design \& Development, Inc, a subcontractor to AlliedSignal. The incident flux distribution on the aperture shield surface from the concentrator was derived for the various cases from calculations done at NASA Lewis (Kerslake and Fincannon, 1995).

The results of the thermal analysis for the three operational scenarios are summarized in Table 1 . The parameters given are peak incident flux, equivalent peak flux in number of suns (at an average low earth orbit solar constant of $0.1417 \mathrm{w} / \mathrm{sq} \mathrm{cm}$ ), maximum temperature of the top (exposed) tungsten foil layer, maximum backplate temperature, and maximum center ring temperature.

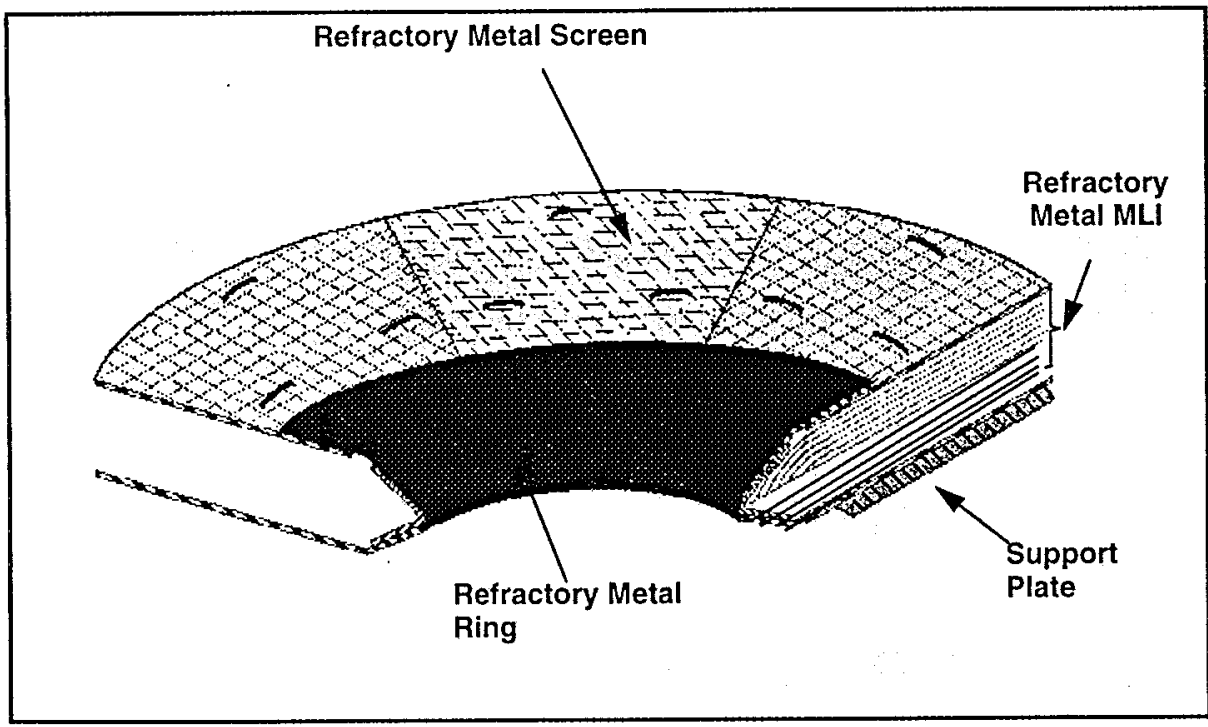

FIGURE 4. APERTURE ASSEMBLY 


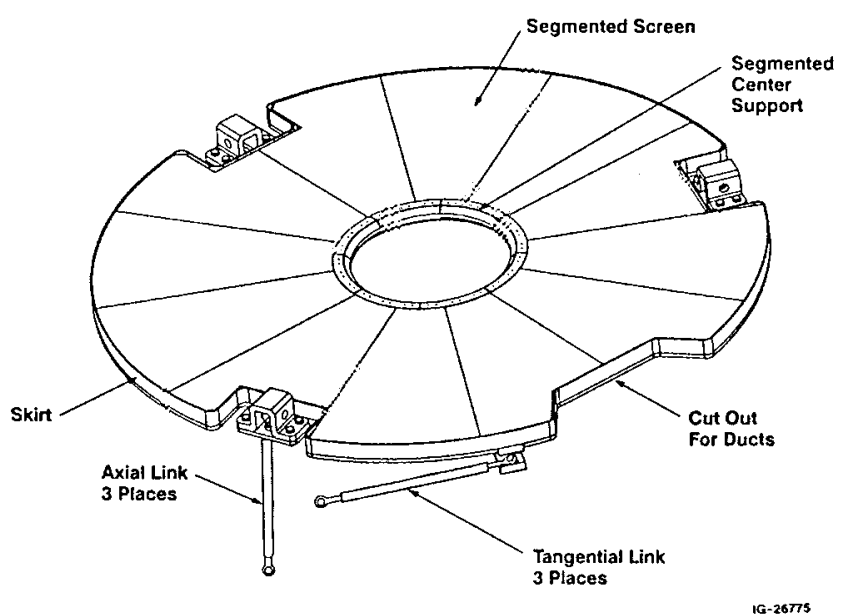

FIGURE 5. APERTURE SHIELD FRONT VIEW
During normal operation, around $2.0 \mathrm{kw}$ (out of $16.8 \mathrm{kw}$ ) spills onto the aperture shield.

The emergency off-pointing requirement is for full sun on the shield for $60 \mathrm{~min}(16.8 \mathrm{kw})$. Thermal analysis was conducted at an off-pointing location of $3.0 \mathrm{deg}$. This location contains the incident energy on the shield, minimizing leakage into the aperture or outside the shield boundaries.

The initial alignment case could occur when the system is first activated after launch. The assumed off-pointing angle of 1.7 deg locates the peak flux on the center ring. Total power on the shield is $10.9 \mathrm{kw}$ (there is significant leakage into the aperture). It is assumed that the maximum time required to move away from the off-point spot is $5 \mathrm{~min}$.

All predicted temperatures (see Table 1) are well within the capability of the materials used.

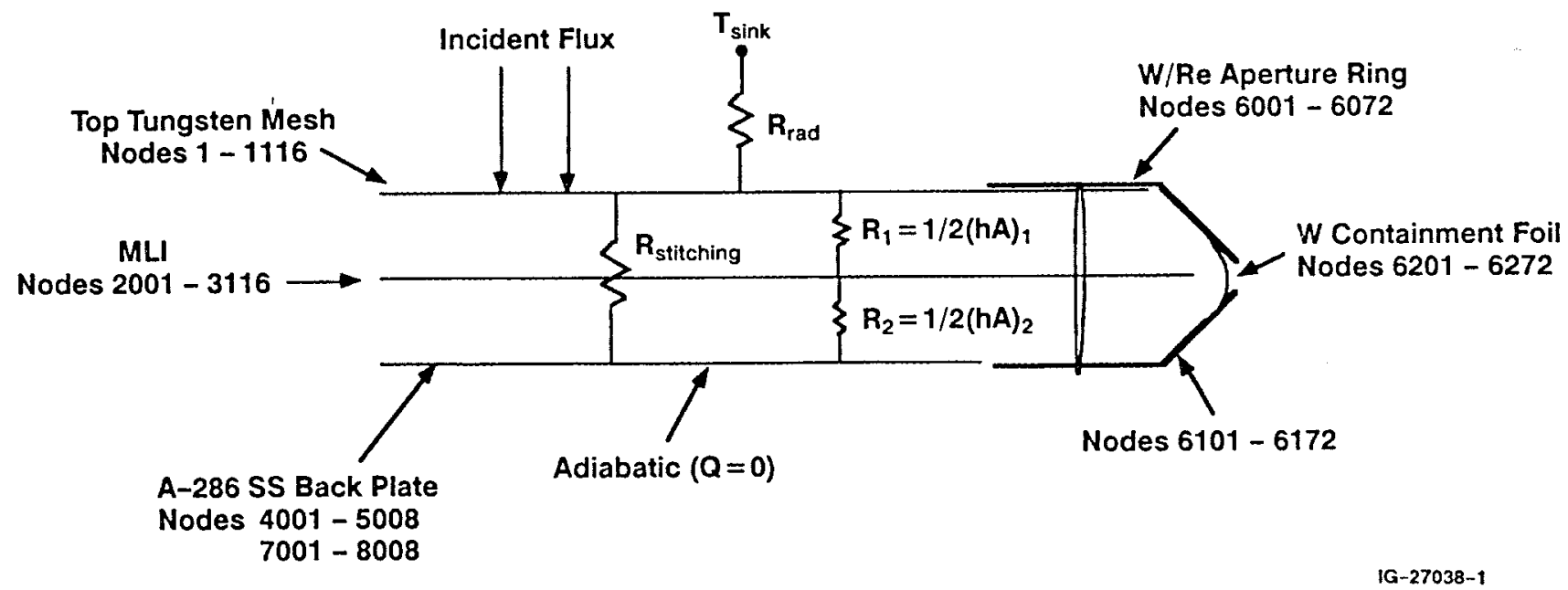

FIGURE 6. APERTURE ASSEMBLY THERMAL MODEL

\begin{tabular}{|c|c|c|c|c|c|}
\hline SUMM & YOF A & ITURE & $\begin{array}{l}\text { LE } 1 \\
\text { SSEMBLY THER }\end{array}$ & IL ANALYSIS & \\
\hline & & & & & \\
\hline Flux Case & $\mathrm{w} / \mathrm{cm}^{2}$ & Suns & $\begin{array}{c}\text { Max. Top Layer } \\
\text { Temp., }{ }^{\circ} \mathrm{F} \\
\end{array}$ & $\begin{array}{l}\text { Max. Backplate } \\
\text { Temp., }{ }^{\circ} \mathrm{F}\end{array}$ & $\begin{array}{c}\text { Max. Center Ring } \\
\text { Temp., }{ }^{\circ} \mathrm{F} \\
\end{array}$ \\
\hline Normal operation & 9.49 & 67.0 & 1312 & 684 & 1318 \\
\hline $\begin{array}{l}\text { Initial alignment at } 1.7 \mathrm{deg} \text { off- } \\
\text { point }\end{array}$ & 82.23 & 580.3 & & & \\
\hline $15 \mathrm{sec}$ & & & 3184 & 16 & 3064 \\
\hline $5 \mathrm{~min}$ & & & 3288 & 99 & 3399 \\
\hline $\begin{array}{l}\text { Emergency off-point at } 3.0 \mathrm{deg} \\
(60 \mathrm{~min})\end{array}$ & 79.23 & 559.1 & 3455 & 1026 & 2505 \\
\hline
\end{tabular}




\section{ON-ORBIT STRESS ANALYSIS}

The on-orbit stresses for the aperture shield assembly are primarily thermal, although there are some low-level vibration stresses. Structural models were prepared for the center ring and backplate support using the ANSYS computer code. The flexible foils were not specifically analyzed, but there should not be any significant thermal stress problems within the foils as they are thin and quite compliant. In addition, the foils are not structural members. The inputs to the stress analysis were the predicted on-orbit temperatures.

For the backplate, the maximum stresses occur for emergency off-point at $60 \mathrm{~min}$. The maximum predicted thermal stress is $43.1 \mathrm{ksi}$. Since the vibration-induced stress is less than $1 \mathrm{ksi}$, the total stress is well below the material yield strength of $78 \mathrm{ksi}$ (at operating temperature).

For the center ring, the maximum stress occurs during the initial alignment period. The peak stress is at $15 \mathrm{sec}$ (not maximum temperature), when the thermal gradients are quite large (see Figure 7). With very low vibration-induced stress, the total stress of about $10 \mathrm{ksi}$ is well below the material yield strength of 14.5 $\mathrm{ksi}$ (taken, for conservatism, at the maximum predicted temperature).

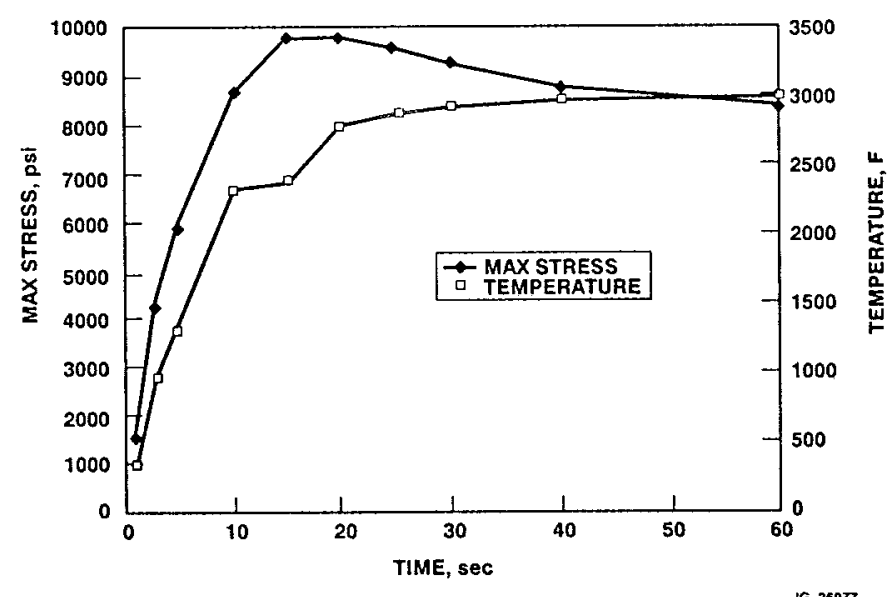

FIGURE 7. CENTER RING MAXIMUM STRESS VERSUS TIME, PSI

\section{LAUNCH LOAD ANALYSIS}

Launch loads were analyzed for the backplate support, attachment wires, and center ring. The ANSYS models were used for the support plate and center ring. Hand calculations were performed for the wire. The components are at ambient temperature during launch. The stress results are summarized in Table 2. All predicted stresses are below allowables.

\begin{tabular}{|c|c|c|}
\hline \multicolumn{3}{|c|}{$\begin{array}{c}\text { APERTURE ASSEMBLY LAUNCH } \\
\text { LOAD STRESS SUMMARY }\end{array}$} \\
\hline Component & $\begin{array}{c}\text { Maximum } \\
\text { Predicted Stress, ksi }\end{array}$ & $\begin{array}{l}\text { Yield Strength, } \\
\text { ksi }\end{array}$ \\
\hline Support plate & 68.6 & 95 \\
\hline Attachment wire & 97.3 & 160 \\
\hline Center ring & 10 & 249 \\
\hline
\end{tabular}

\section{CONCLUSION}

A full-size aperture shield assembly for the heat receiver component of the joint U.S./Russia SDFD program was fabricated. This unit was essentially identical to the flight configuration, with the exception that nickel foils were substituted for the refractory metal foils required for the flight unit. In addition, a thermal shock test aperture shield assembly was fabricated. This unit is shown in Figures 8 and 9. This test article utilized the flight refractory metals and was subjected to high-flux testing in the solar simulator test rig at NASA Lewis. This testing is described in a companion paper (Kerslake, et al, 1997).

The aperture shield assembly was designed to accommodate all on-orbit and launch loads. Detailed analysis has indicated that all loads can be comfortably accommodated.

The SDFD mission was demanifested from the ISS Phase 1 Space Shuttle Program. NASA Lewis is proposing to use the fabricated flight hardware as part of an all-American flight demonstration on the ISS in 2002.

\section{ACKNOWLEDGMENTS}

The authors would like to acknowledge the significant contributions made to the program by Rich Jetley and Frank Huang.

\section{REFERENCES}

Kerslake, T., and Fincannon, J., 1995, "Analysis of Solar Receiver Flux Distributions for U.S./Russia Solar Dynamic System Demonstration on the Mir Space Station," Paper 95-136, 30th IECEC.

Kerslake, T., Mason, L, and Strumpf, H., 1997, "High-Flux, High-Temperature Thermal Vacuum Qualification Testing of a Solar Receiver Aperture Shield," Paper 97236, 32nd IECEC.

Strumpf, H., Krystkowiak, C., and Killackey, J., 1993, "Design of the Heat Receiver for the Solar Dynamic Ground Test Demonstrator Space Power System," Paper 93028, 28th IECEC.

Strumpf, H., Krystkowiak, C., and Klucher, B., 1995, “Design of the Heat Receiver for the U.S./Russia Solar Dynamic Power Joint Flight Demonstration," Paper 95-168, 30th IECEC.

Strumpf, H. and Trinh, T., 1996, “On-Orbit Performance Prediction of the Heat Receiver for the U.S./Russia Solar Dynamic Power Flight Experiment," Paper 96322, 31st IECEC.

Wanhainen, J. and Tyburski, T., 1995, "Joint U.S./Russian Solar Dynamic Flight -Demonstration Project Plan," 30th IECEC, pp. 417-420. 


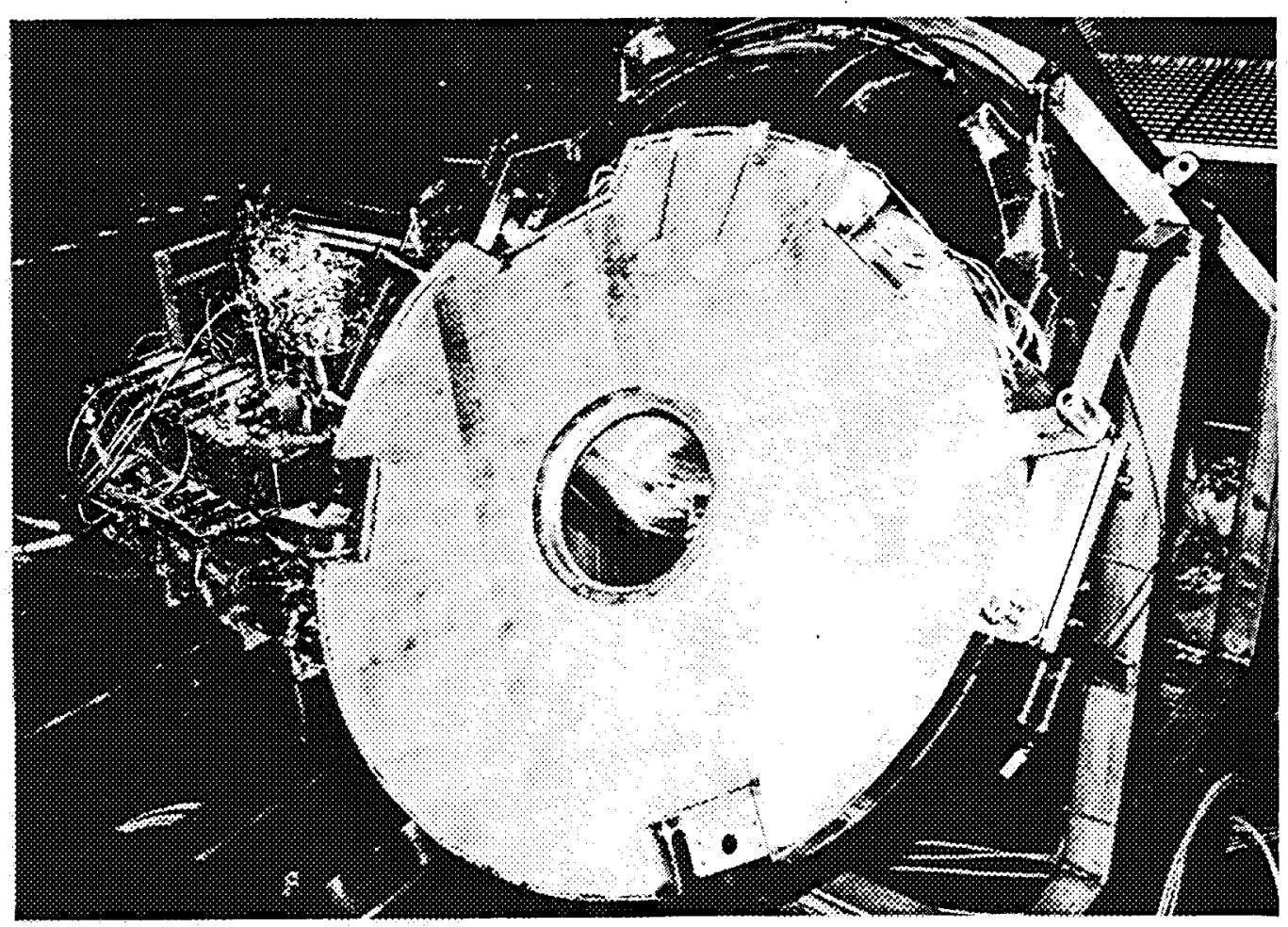

FIGURE 8. APERTURE SHIELD TEST ARTICLE

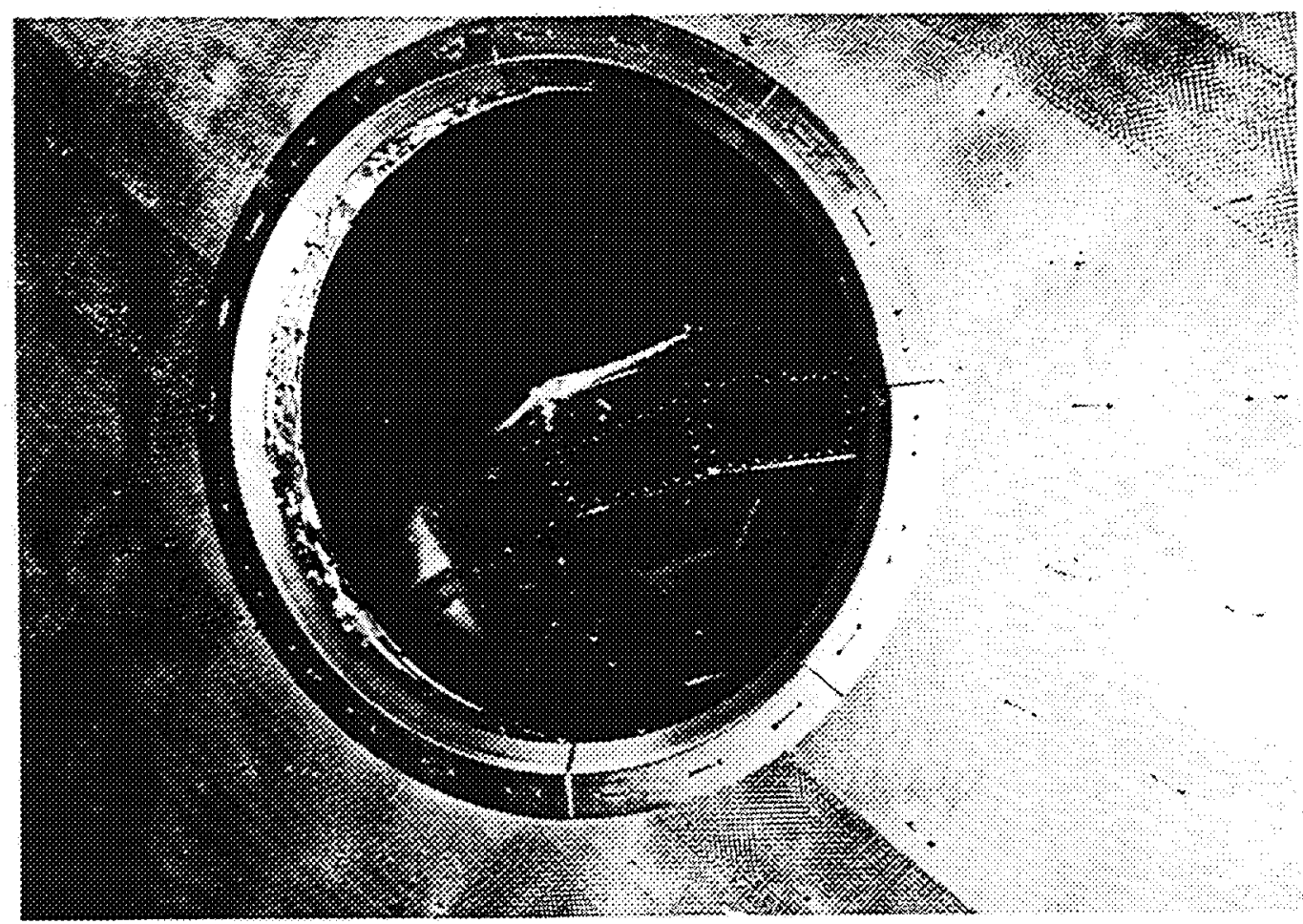

FIGURE 9. TEST ARTICLE APERTURE RING DETAILS 
Public reporting burden for this collection of information is estimated to average 1 hour per response, including the time for reviewing instructions, searching existing data sources, gathering and maintaining the data needed, and completing and reviewing the collection of information. Send comments regarding this burden estimate or any other aspect of this coslection of information including suggestions for reducing this burden, to Washington Headquarters Services, Directorate for information Operations and Reports, 1215 Jefferson Davis Highway, Suite 1204, Arlington, VA 22202-4302, and to the Office of Management and Budget, Paperwork Peduction Project (0704-0188), Washington, DC 20503.

\begin{tabular}{|l|l|l|}
\hline 1. AGENCY USE ONLY (Leave blank) & $\begin{array}{c}\text { 2. REPORT DATE } \\
\text { July } 1997\end{array}$ & $\begin{array}{r}\text { 3. REPORT TYPE AND DATES COVERED } \\
\text { Technical Memorandum }\end{array}$
\end{tabular}

\section{TITLE AND SUBTITLE}

5. FUNDING NUMBERS

Design and Analysis of the Aperture Shield Assembly for a Space Solar Receiver

6. AUTHOR(S)

WU-547-10-41

Hal Strumpf, Tuan Trinh, William Westelaken, Christopher Krystkowiak,

Vahe Avanessian, and Thomas W. Kerslake

7. PERFORMING ORGANIZATION NAME(S) AND ADDRESS(ES)

8. PERFORMING ORGANIZATION REPORT NUMBER

National Aeronautics and Space Administration

Lewis Research Center

Cleveland, Ohio 44135-3191

E-10802

9. SPONSORING/MONITORING AGENCY NAME(S) AND ADDRESS(ES)

10. SPONSORING/MONITORING AGENCY REPORT NUMBER

National Aeronautics and Space Administration

Washington, DC 20546-0001

NASA TM-107500

IECEC-97347

\section{SUPPLEMENTARY NOTES}

Prepared for the 32nd Intersociety Energy Conversion Engineering Conference cosponsored by AIChE, ANS, SAE, AIAA, ASME, and IEEE, Honolulu, Hawaii, July 27-August 1, 1997. Hal Strumpf, Tuan Trinh, William Westelaken, Christopher Krystkowiak, and Vahe Avanessian, AlliedSignal Aerospace Equipment Systems, 2525 West 190th Street, Torrance, California 90509; Thomas W. Kerslake, NASA Lewis Research Center. Responsible person, Thomas W. Kerslake, organization code 6920, (216) $433-5373$.

\begin{tabular}{l|l} 
12a. DISTRIBUTION/AVAILABILITY STATEMENT & 12b. DISTRIBUTION CODE
\end{tabular}

Unclassified - Unlimited

Subject Categories 18 and 20

This publication is available from the NASA Center for AeroSpace Information, (301) 621-0390.

\section{ABSTRACT (Maximum 200 words)}

A joint U.S./Russia program has been conducted to design, develop, fabricate, launch, and operate the world's first space solar dynamic power system on the Russian Space Station Mir. The goal of the program was to demonstrate and confirm that solar dynamic power systems are viable for future space applications such as the International Space Station (ISS). The major components of the system include a solar receiver, a closed Brayton cycle power conversion unit, a power conditioning and control unit, a solar concentrator, a radiator, a thermal control system, and a Space Shuttle carrier. Unfortunately, the mission was demanifested from the ISS Phase 1 Space Shuttle Program in 1996. However, NASA Lewis is proposing to use the fabricated flight hardware as part of an all-American flight demonstration on the ISS in 2002. The present paper concerns the design and analysis of the solar receiver aperture shield assembly. The aperture shield assembly comprises the front face of the cylindrical receiver and is located at the focal plane of the solar concentrator. The aperture shield assembly is a critical component that protects the solar receiver structure from highly concentrated solar fluxes during concentrator off-pointing events. A full-size aperture shield assembly was fabricated. This unit was essentially identical to the flight configuration, with the exception of materials substitution. In addition, a thermal shock test aperture shield assembly was fabricated. This test article utilized the flight materials and was used for highflux testing in the solar simulator test rig at NASA Lewis. This testing is described in a companion paper.

\section{SUBJECT TERMS}

Solar dynamic power systems; Space stations; Heat shielding; High temperature; Thermal stresses; Solar energy; Heat flux; Mir Space Station

\begin{tabular}{|c|c|}
\hline $\begin{array}{c}\text { 17. SECURITY CLASSIFICATION } \\
\text { OF REPORT } \\
\text { Unclassified }\end{array}$ & $\begin{array}{c}\text { 18. SECURITY CLASSIFICATION } \\
\text { OF THIS PAGE } \\
\text { Unclassified }\end{array}$ \\
\hline
\end{tabular}

\section{SECURITY CLASSIFICATION OF ABSTRACT Unclassified}

\section{NUMBER OF PAGES}

16. PRICE CODE

$\mathrm{A} 02$

20. LIMITATION OF ABSTRACT

